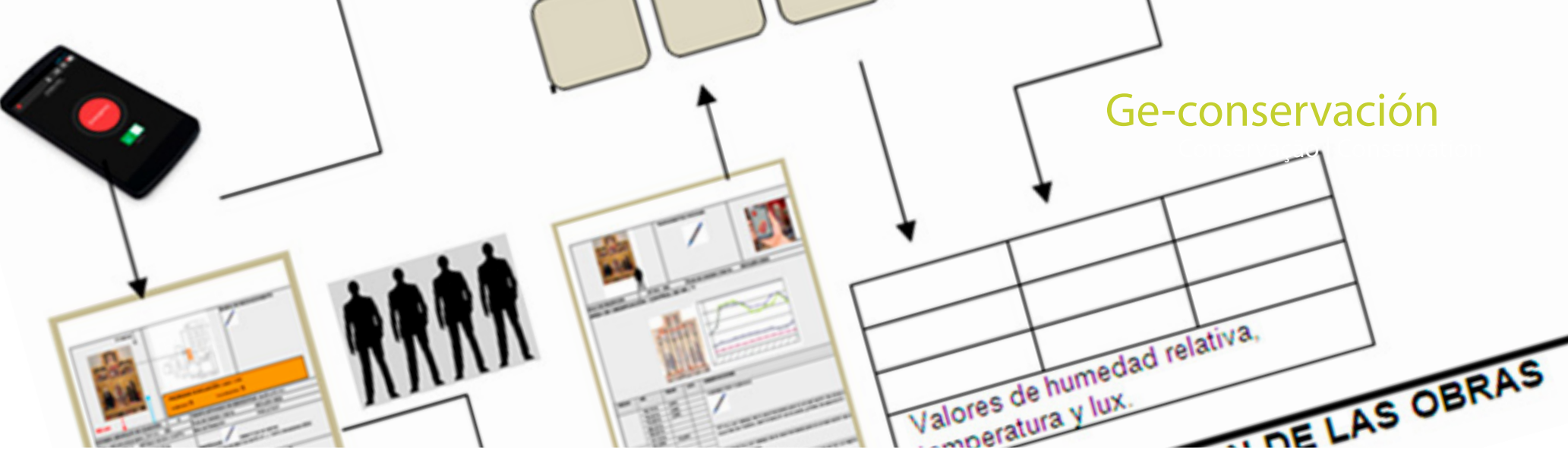

\title{
Fichas para la evacuación y rescate de la pintura de caballete - retablos
}

\author{
Inmaculada Chuliá Blanco
}

Resumen: El modelo de ficha para la evacuación y rescate de la pintura de caballete fue diseñado inicialmente para el Museo de Bellas Artes de Valencia, con más de 400 registros de la colección permanente, la mayoría pinturas de caballete y retablos de grandes dimensiones.

Es un sencillo formato destinado al procedimiento operativo del rescate y estabilización de los bienes, que recoge la máxima cantidad de datos sobre las características técnicas de las obras de la colección.

Las fichas son una herramienta para la coordinación y ordenación de la evacuación de los objetos durante un siniestro y su manipulación sin riesgo. Su diseño permite incluir características técnicas de otras tipologías como colecciones textiles, objetos etnográficos, trabajos sobre papel, cerámica o escultura, entre otros. Y acepta también, incorporar campos con estrategias para mejorar la respuesta de los equipos de intervención. El proyecto está pensado para exportar la información registrada en una aplicación App de emergencias.

Palabras clave: seguridad, tipos de colecciones, fichero, pictogramas, emergencias

\section{Files for the evacuation and rescue of easel painting - altarpieces}

Abstract: The file model for the evacuation and rescue of easel paintings was initially designed for the Museum of Fine Arts of Valencia. With more than 400 registered items in its permanent collection, the majority is comprised of easel paintings and large altarpieces.

It is a simple format for the rescue operating procedure and stabilization of art pieces, and collects the maximum amount of data on the technical characteristics of the works in the collection.

The files are a tool for a coordinated evacuation order of the objects under threat, and how they should be handled without further risk. Its design allows the inclusion of technical characteristics of other types such as textile collections, ethnographic objects, written works, pottery, and sculpture among others. It also incorporates fields which describe strategies to improve the response time for intervention teams. This information is designed to be exported and distributed through an App in case of emergency.

Keyword: security, types of collections, file, pictograms, emergencies.

\section{Fichas para a evacuação e resgaste da pintura de cavalete -retábulos}

Resumo: O modelo de ficha para a evacuação e resgate da pintura de cavalete foi criado inicialmente para o Museu de Belas-Artes de Valencia. Com mais de 400 registros da coleção permanente, a maioria são pinturas de cavalete e retábulos de grandes dimensões.

Tem um formato simples destinado ao procedimento operativo de resgate e estabilização dos bens, que recolhe a máxima quantidade de dados sobre as características técnicas das obras da coleção.

As fichas são uma ferramenta para uma ordem coordenada de evacuação de objetos em risco, bem como de manuseamento. O design da ficha permite incluir características técnicas de outras tipologias, tais como têxteis, objetos etnográficos, trabalhos sobre papel, cerâmica e escultura, entre outros. Aceita também a incorporação de campos com estratégias para melhorar a resposta das equipas de intervenção. O projeto está pensado para exportar a informação registrada para uma aplicação App de emergências.

Palavras-chave: segurança, tipos de coleções, ficheiro, pictogramas, emergências 


\section{Introducción}

Reconocida como una disciplina, la conservación preventiva tiene entre sus actividades acciones encaminadas a la salvaguarda y rescate de las colecciones frente a las emergencias, condicionados por la siniestralidad sobre estas y las graves consecuencias para los materiales. Uno de sus objetivos son las colecciones de los museos donde se concentra gran número de objetos muy diversos.

Ante la probabilidad real de una emergencia, los museos deben estar preparados y sobre todo organizados con estrategias para la evacuación y recuperación de los bienes de una forma protocolizada aun antes de que el riesgo se produzca. Cualquier siniestro que afecte a una colección, y que aparece de muchas formas, con un rango de raro a catastrófico, pasando por las amenazas diarias puede desencadenar el caos y provocar una situación estresante que se complicará sin un programa de actuación.

Ese riesgo debe ser evaluado en el Plan de emergencias de una colección (MCCRACKEN, 1995) y debe vincularse al Plan de Autoprotección. Está demostrado que una buena coordinación durante las primeras horas puede evitar un porcentaje elevado de pérdidas y daños en la colección.

Pero redactar un plan de emergencia para la colección no es suficiente, la institución debe preparar con formación y entrenamiento a su personal en la lucha contra los desastres. Es una gestión complicada porque intervienen muchos equipos, que a través de diferentes líneas de trabajo establecen una red de servicios y procedimientos. De ahí que la coordinación sea ordenada y configurada previamente.

Cuando la institución elabora su propio plan de rescate para su colección (DORGE, 2004) genera una nueva documentación $^{[1]}$ que debe incluir dentro del sistema documental (CARRETERO 1997: p. 11-29). Es una de las funciones prioritarias para la seguridad de la colección y la organización de los objetos (AMBOUROUÈ 2010).

Durante un siniestro es imprescindible disponer de una información técnica sobre los objetos de la colección que no suele señalarse en el registro de la institución.

Debe contemplar diversidad, características, intereses, capacidades y necesidades de los fondos. Hablamos del posible rescate de material arqueológico, libros y manuscritos, material etnográfico, colecciones audiovisuales, muebles, fotografías, artículos tecnológicos, textiles, pintura sobre lienzo o tabla, esculturas, dibujos, grabados, xilografías, artes decorativas, etc.

Mientras este activa una emergencia en una colección es necesario vincular su registro con la seguridad, y destrezas con la capacidad de organización de los equipos humanos disponibles en cada institución.
No existen muchas referencias o directrices relacionadas con la gestión del riesgo o sobre procedimientos de rescate. Los contenidos de los escasos patrones y herramientas disponibles, tanto nacionales como internacionales, con el paso de los años y desde el punto de vista estratégico, deben modificarse y buscar una normalización de los campos informativos. Aunque no son patrones equiparables se examinaron sus formatos, el lenguaje utilizado, la propuesta informativa, el diseño y las funciones operativas para el rescate de los objetos.

Tras este análisis se ha propuesto un nuevo modelo de ficha para la evacuación y rescate de Pintura que contribuye con enfoques necesarios durante la evacuación de esta tipología de material. En un mismo formato están definidas nuevas instrucciones para el rescate según la prioridad de la pintura de caballete (creando una jerarquía de rescate): su localización, el procedimiento de desmontaje, el sistema de anclaje y bloqueos de seguridad, las instrucciones de maniobra, el soporte humano necesario, la dimensión de la o las vías de evacuación, su recorrido y el lugar de recepción. Contempla a los equipos de intervención y el grupo designado para realizar el triaje inicial de evaluación. Además dispone de campos y gráficas para incorporar los valores de monitoreo de la sala para la estabilización de los materiales.

\section{Objetivos}

La creación de un FICHERO DE EVACUACIÓN Y RESCATE DE LA PINTURA DE CABALLETE, pretende conseguir un innovador expediente del objeto, renovando campos informativos. El objetivo principal es determinar un modelo abierto, que soporte una estructura troncal con todas las referencias que se necesitan durante el rescate de las obras, principalmente frente a siniestros y su manipulación durante la emergencia, pero con la versatilidad de modificar campos informativos adaptándose al tipo de colección. Un modelo que describa las estrategias de gestión antes, durante y tras las operaciones de salvamento.

Para ello la ficha, en su aspecto formal, debe introducir los elementos informativos y técnicos necesarios para las actividades durante la organización de los equipos de rescate, la evacuación y las primeras acciones para estabilizar los materiales afectados.

Entre los objetivos específicos se propone, un patrón de respuesta con la incorporación de prototipos gráficos junto a normas de conducta. Respecto a la comunicación durante la resolución del conflicto, el uso combinado de textos y pictogramas tiene como misión la comprensión rápida de la información. Esta asociación facilita al usuario su asimilación y ayuda a establecer pautas de actuación coordinadas entre los equipos de intervención. 


\section{Hipotesis}

Un modelo de ficha para la evacuación y rescate unido a su expediente de evaluación, manipulación, estabilización y seguimiento, multiplica las ventajas al capturar, gestionar, almacenar, preservar y difundir contenidos y documentos relacionados con los procesos organizativos en un mismo formato y cumple con la seguridad de los objetos. Además admite una metodología que busca multiplicar las opciones de supervivencia de las colecciones frente a un siniestro.

\section{Metodología: mecanismos de la información}

La formulación de una metodología se apoya siempre en la necesidad de responder eficientemente y actuar con operatividad en un entorno complejo (genérico y específico)sujeto a un periodo de crisis. Por esto el diseño de una ficha de evacuación debe facilitar la orientación y el tránsito hacia una respuesta competitiva.

Para construir una propuesta contextualizada y validada, en el procedimiento metodológico se ha utilizado el análisis del método comparativo, recogiendo los criterios técnicos y profesionales buscados.

\section{Estudio de patrones de referencia y herramientas disponibles}

En los modelos y herramientas de la mayoría de las instrucciones que han desarrollado sus propios planes de emergencia o autoprotección, predomina una comunicación establecida a través del texto escrito. El aspecto formal es similar.

Sin embargo, durante la respuesta a los desastres, tanto neurólogos como psicólogos advierten que la mayoría de las personas no asimilan bien un lenguaje con textos cortos.

Esto plantea una revisión de las unidades informativas necesarias y su lenguaje: cuáles son los contenidos y su formato.

A la hora de proponer un sistema de documentación especializado dentro del campo de las emergencias para las colecciones, es adecuado plantearlo transversal a las aéreas básicas de actuación en los museos:administración, seguridad y conservación e investigación. En principio ninguna de estas coordina cualquier control o gerencia de los riesgos sobre las colecciones. Es una actividad nueva y omitida que debe formar parte de la misión de gestión de la institución (CHULIÁ 2016).

Como referencia internacional, están las fichas técnicas del CIDOC $^{[2]}$, que describen de un modo sencillo y en ocho etapas, el proceso de registro y catalogación de un objeto. Reúnen las directrices para la documentación de los bienes patrimoniales desarrollados por un grupo de trabajo dirigido por The Getty Center y la College Art Association of América (CAA).

En España, a partir de 1942 (FABRE 2009: p. 51), se acordó para la redacción del inventario general, catálogos y registros en los museos el uso de unas 102 instrucciones. Estas instrucciones, actualizadas y simplificadas con el tiempo (CARRETERO et al.1998), no han generado expedientes referentes a la conservación preventiva y mucho menos tratan de cuestiones relativas a los riesgos para los objetos en los museos, a pesar del intento de normalización del "Plan Circe"(LEDESMA 1992: p. 33-37) años después.

En su evolución, con la implantación del programa DOMUS ${ }^{[3]}$, el paso de lo analógico a lo digital facilitó un modelo normalizado permitiendo relacionar datos fundamentales como el ingreso, los movimientos internos y externos de una pieza del museo, el análisis y tratamientos de restauración, etc. [figura 1]. Sin embargo, persiste un vacío en el registro de la relación de las colecciones con los siniestros, implícitos en los 10 agentes de riesgo que alertan los investigadores canadienses liderados por Stefan Michalski (MICHALSKI 2009), como el peligro de manipulación, montaje, conservación o transporte.

Los conceptos del riesgo, emergencia o desastres en la práctica documental de las instituciones aparecen con la publicación en el año 2008, de la Guía para elaborar un Plan de Protección de Colecciones ante Emergencias, y revisados en el Plan Nacional de Emergencias y Gestión de Riesgos en el Patrimonio Cultural del 2015. Excepcionalmente encontramos iniciativas aisladas en algunos museos que ya poseen, con la creación de planes de emergencias sobre sus colecciones, su propia documentación o fichas de trabajo ${ }^{[4]}$.

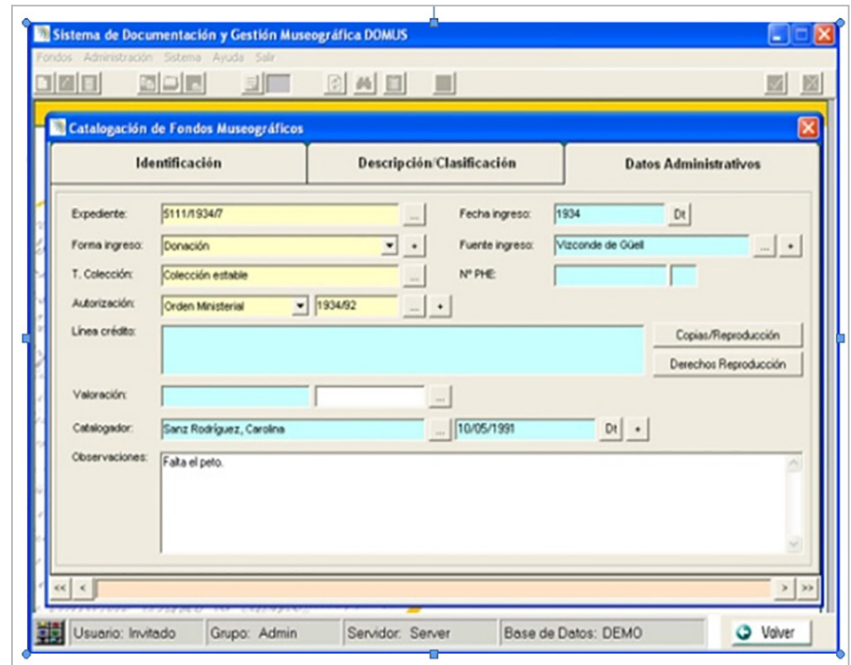

Figura 1.- Sistema de documentación y gestión museográfica. Fuente: Sistema de documentación y Gestión museográfica, DOMUS. 
Tabla 1.- Relación de formularios propuestos en la Guía para un plan de protección de colecciones ante emergencias, Madrid. Ministerio de Cultura. Secretaría General Técnica. Fuente: Autor

\begin{tabular}{|c|c|c|}
\hline Ficha 0.: & IDENTIFICACION DEL MUSEO & DOCUMENTO VINCULADO A OTRO DOCUMENTO: \\
\hline Ficha 1.1.: & $\begin{array}{l}\text { Identificación de las zonas con colección } \\
\text { dentro del museo y sistemas de protección }\end{array}$ & $\begin{array}{l}\text { Plano de la ficha 1.1. Zonas y sistemas de protección } \\
\text { Ficha 1.2.a. Evaluación de riesgos por zonas } \\
\text { Ficha 1.2.b. Evaluación de riesgos por zonas }\end{array}$ \\
\hline Ficha 2.1.: & Recursos humanos & \\
\hline Ficha 2.2.: & Recursos materiales para la evacuación & $\begin{array}{l}\text { Plano de la ficha 2.2. Plano del Museo con los espacios disponibles } \\
\text { para la evacuación de las colecciones y vías de evacuación a } \\
\text { espacios externos o internos } \\
\text { Planos de las fichas 2.2.a., 2.2.b., 2.2.c., etc. Planos de los edificios } \\
\text { externos con espacios disponibles para la evacuación (opcionales) }\end{array}$ \\
\hline Ficha 3.1.: & Minimización de riesgos & \\
\hline Ficha 3.2.: & Jerarquización de piezas/colecciones & \\
\hline Ficha 3.3.: & $\begin{array}{l}\text { Listado de piezas/colecciones propuestas } \\
\text { para su evacuación }\end{array}$ & \\
\hline Ficha 3.4.: & $\begin{array}{l}\text { Identificación de las piezas/colecciones } \\
\text { seleccionadas }\end{array}$ & $\begin{array}{l}\text { Anexo a la Ficha 3.4. Cuadro de vulnerabilidad de materiales frente } \\
\text { a distintos tipos de riesgos } \\
\text { Plano de la ficha 3.4. Localización de las piezas seleccionadas }\end{array}$ \\
\hline Ficha 3.5.: & Identificación de los equipos & \\
\hline Ficha 3.6.: & Formación $\mathrm{v}$ simulacros & \\
\hline Ficha 3.7.: & $\begin{array}{l}\text { Identificación de los botiquines de } \\
\text { emergencia }\end{array}$ & $\begin{array}{l}\text { Plano de la Ficha 3.7. Ubicación de los almacenes de materiales de } \\
\text { emergencia }\end{array}$ \\
\hline Ficha 3.8.: & $\begin{array}{l}\text { Identificación de los almacenes de } \\
\text { emergencia }\end{array}$ & $\begin{array}{l}\text { Plano de la Ficha 3.8. Ubicación de los almacenes de emergencias } \\
\text { internos y externos -opcionales) }\end{array}$ \\
\hline Ficha 3.9.: & Recursos externos al museo & \\
\hline Ficha 4.1.: & Control de evacuación: salida & PROCEDIMIENTO OPERATIVO \\
\hline Ficha 5.1.: & Control de evacuación: llegada & RECUPERACION \\
\hline
\end{tabular}

El expediente generado en la publicación de la Guía para elaborar un Plan de protección de colecciones ante emergencias contempla todos los aspectos enfocados con la prevención y la autoprotección, pero el número de formularios necesarios a desarrollar crea un documento demasiado complejo, amplio y diversificado (CULUBRET et al. 2008) [ [Tabla 1]

Respecto al formulario de las fichas de salvamento [figura 2] propuesto en el documento del Plan nacional de Emergencias y Gestión de riesgos en el patrimonio cultural (pág. 127), tanto los contenidos como las medidas incluidas de evacuación, están pensados hasta la asignación del responsable de recepción del objeto.

Entre las funciones asignadas y bien definidas del responsable de recepción están la identificación y clasificación de las obras y objetos de acuerdo con un sistema de prioridad determinado por la naturaleza de los materiales o la gravedad de los daños; en estrecha colaboración con el responsable del inventario y del traslado de las obras, objetos y piezas de equipo. El responsable de recepción también se encarga de formar los equipos de trabajo y asignar las operaciones de limpieza superficial, de estabilización o de protección, elaborando un nuevo informe para el coordinador principal.

Sin embargo, en el formulario no están contempladas todas estas actividades. Ahí radica su debilidad. Para la evaluación de daños se propone un nuevo modelo de formulario y un tercer modelo, para el control de inventario en actuaciones de salvamento ${ }^{[5]}$.

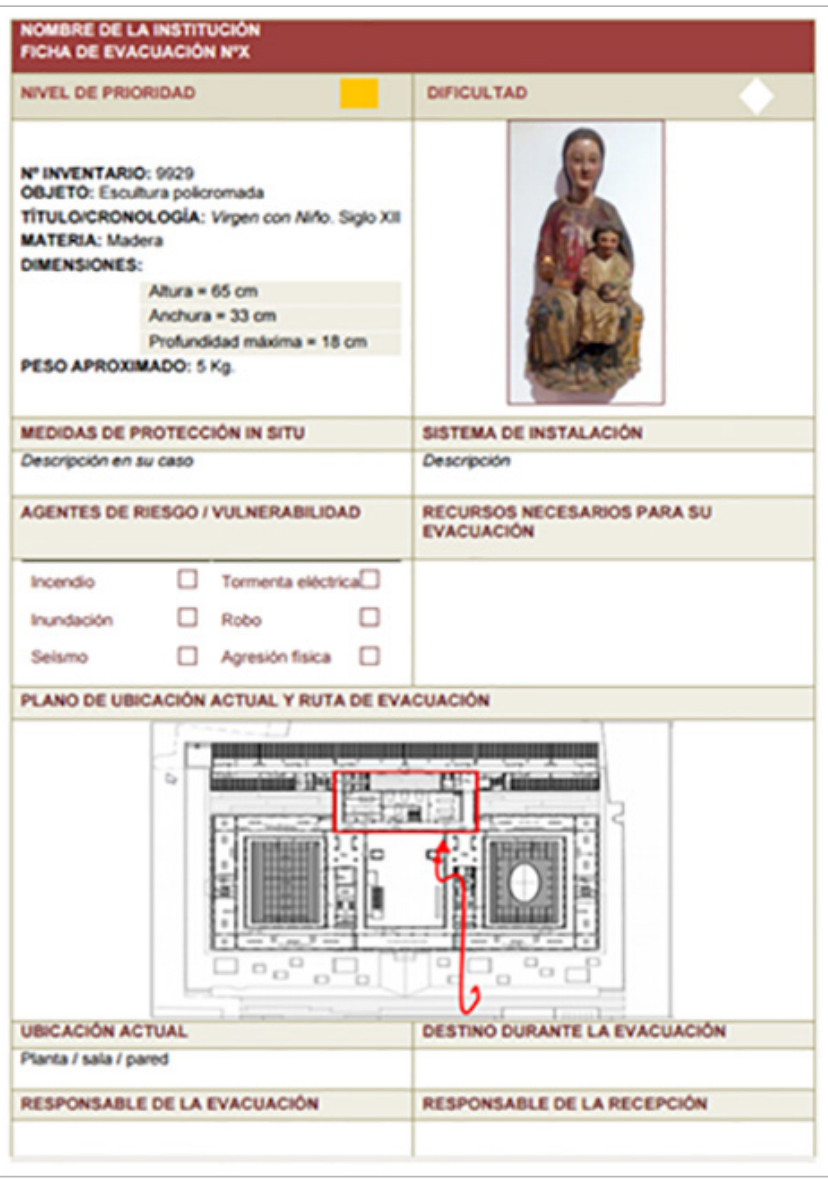

Figura 2.- Modelo de ficha de evacuación propuesta en el documento del Plan nacional de Emergencias y Gestión de riesgos en el patrimonio cultural, p 127. 
Una situación de emergencia no puede considerarse finalizada solo con el rescate de los objetos. La emergencia está controlada cuando los objetos afectados están estabilizados. Se debe mantener la seguridad documental de todo el proceso.

En el Museo Guggengheim de Bilbao, que tiene operativo su propio plan de emergencias para la colección (en vigor desde el año 2003), las obras situadas en las zonas privadas tienen en sus cartelas informativas [figura 3], los datos y las pautas frente a un siniestro (ARISTEGUI 2004: p. 29-32). Su lenguaje utiliza pictogramas y textos cortos, describe las características y composición de los objetos, los datos de atribución y un código de color relacionado con la jerarquía del rescate.

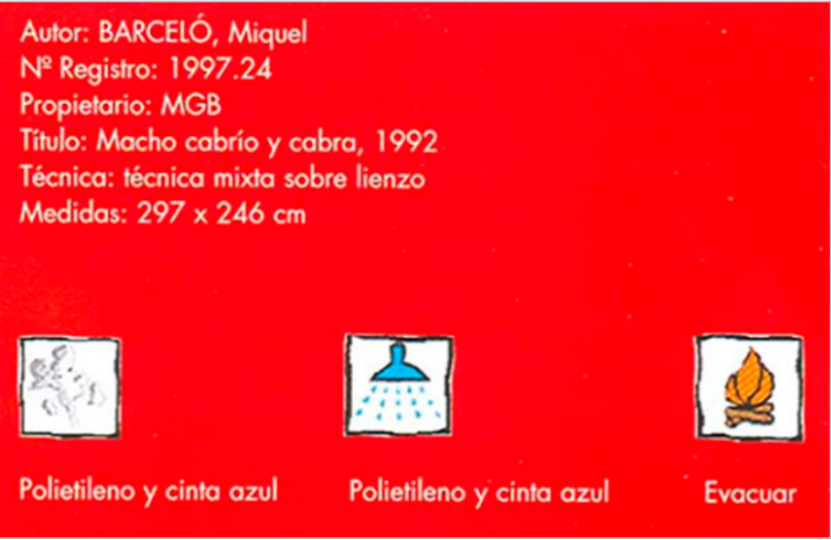

Figura 3.- Cartela de información para las zonas privadas con colección, (almacenes). Fuente: Museo Guggenheim Bilbao.

Aunque es un gran avance, esta información presenta debilidades respecto a la operatividad de un rescate. Están ausentes los datos relacionados con el protocolo de manipulación del objeto o el número de operarios necesarios para su transporte y tampoco está detallada la metodología de recepción de los objetos y su triaje.

En el 2012, se dio a conocer una aplicación gratuita para pequeños museos, desarrollado por el centro Nacional para la Preservación de tecnología y formación (NCPTT) sobre la información contenida en la rueda deslizable de Heritage Preservation $^{[6]}$.

Es una aplicación (App) que contiene la información para la recuperación después de un desastre, Heritage preservation's emergency response and salvage Wheel. En esta se recomiendan las acciones durante las primeras 48 horas después de un desastre para colecciones mixtas con menos recursos ${ }^{[7]}$. A lo largo de varias pantallas se describen las etapas críticas de la respuesta, tales como la estabilización del medio ambiente o la evaluación de los daños. Las técnicas de recuperación que se describen, sirven de ayuda para el rescate de nueve tipos de colecciones: fotografías, libros y documentos, pinturas, documentos electrónicos, textiles, muebles, cerámica, piedra, metal o materiales inorgánicos [figura 4].

Es una herramienta bastante completa, pero la ausencia de una información más técnica sobre los objetos con su estudio material pone en riesgo el éxito del rescate. El primer bloque informativo recoge los contenidos del plan de autoprotección y en el segundo se describen las técnicas de recuperación, con un modelo de información muy genérico sin organización perceptual (OVIEDO 2004: p. 89-96).

Aunque parte de su contenido se necesita en un plan de emergencia de colecciones, no están definidos los equipos de rescate, las vías de evacuación, el triaje y clasificación de los objetos o las técnicas de recuperación. Solo aparecen técnicas de recuperación frente a los objetos afectados por una inundación. Además el formato no permite la auditoría del siniestro, con la incorporación de grabaciones, vídeos o el registro de imágenes.

A pesar de la amplitud del modelo, entre sus carencias están unas limitadas instrucciones.

Cuidado porque las condiciones ambientales de cualquier siniestro, la iluminación insuficiente o la posibilidad de riesgos añadidos hacen que las funciones asistenciales se deban desarrollar bajo fuertes preceptos de seguridad,
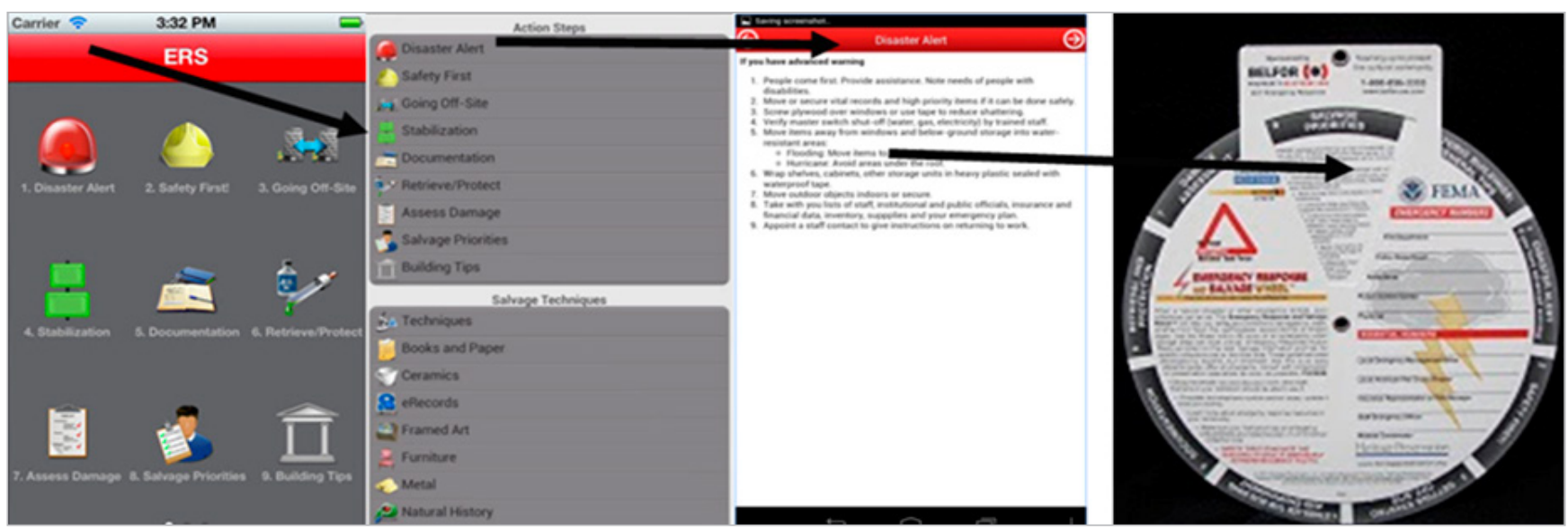

Figura 4.- Aplicación de Heritage preservation's emergency response and salvage Wheel. 
conocimiento y destreza. En cualquier situación crítica, una actuación masiva y desordenada puede generar más caos.

Otro complemento disponible para los museos son unas plantillas Ilamadas Pocket Response Plan, diseñada en el 2006 por $\operatorname{CoSa}^{[8]}$ Es un documento de bolsillo del tamaño de una tarjeta para llevar encima [figura 5]. Constituye un formato a dos caras con las instrucciones durante la alerta de emergencia y las primeras intervenciones. En el lado $A$ está contemplado quienes forman el equipo de desastres, junto al directorio local de comunicación esencial para las emergencias: servicios públicos, proveedores y organismos esenciales (plan de autoprotección). En la otra cara, aparecen las tareas que deben realizarse tras la incidencia: un cuestionario y una lista organizada de acciones que cada individuo debe realizar durante las primeras 24 a 72 horas tras un desastre.

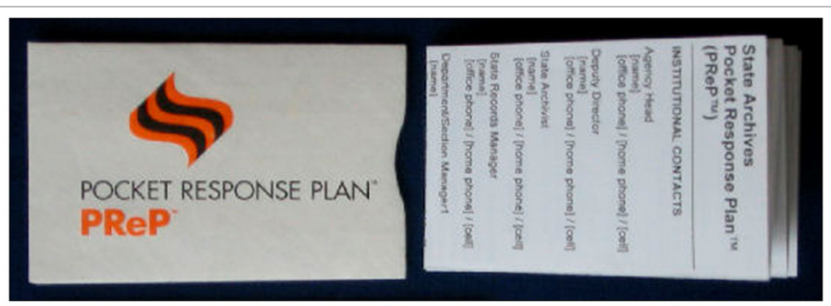

Figura 5.- Plantilla Plan de Respuesta ${ }^{\mathrm{TM}}\left(\right.$ PREP $\left.^{\mathrm{TM}}\right)$.
En esta plantilla, no están definidas las estrategias de rescate, estabilidad o competencias de los equipos de intervención.

En el año 2014, se dio a conocer un artículo dentro del 17th Triennial Conference del ICCOM-CC, Organizational tools for salvage operations (VON LERBER 2004: p.1519) con una ficha-hoja de estabilización para tapices $y$ alfombras [Prevart GmbH 2016], [figura 6]. Contribuye con las necesidades de procedimientos de actuación frente a una emergencia, su lenguaje busca la respuesta efectiva de sus usuarios con la incorporación en el discurso, de imágenes asociadas a textos cortos. Cuando se combinan ambos lenguajes, las oportunidades de comprensión y memorización se multiplican.

\section{Definición de la nueva estrategia}

\section{-Determinar un reconocimiento rápido de comunicación}

Las fichas de rescate deben establecer un formato con unidades de organización perceptiva estructuradas según el orden de necesidad jerárquica para el rescate. Con un lenguaje mediante modelos de reconocimiento directo con textos, palabras, clausulas o letras, asociadas a pictogramas donde el receptor sea capaz de extraer la información con facilidad.
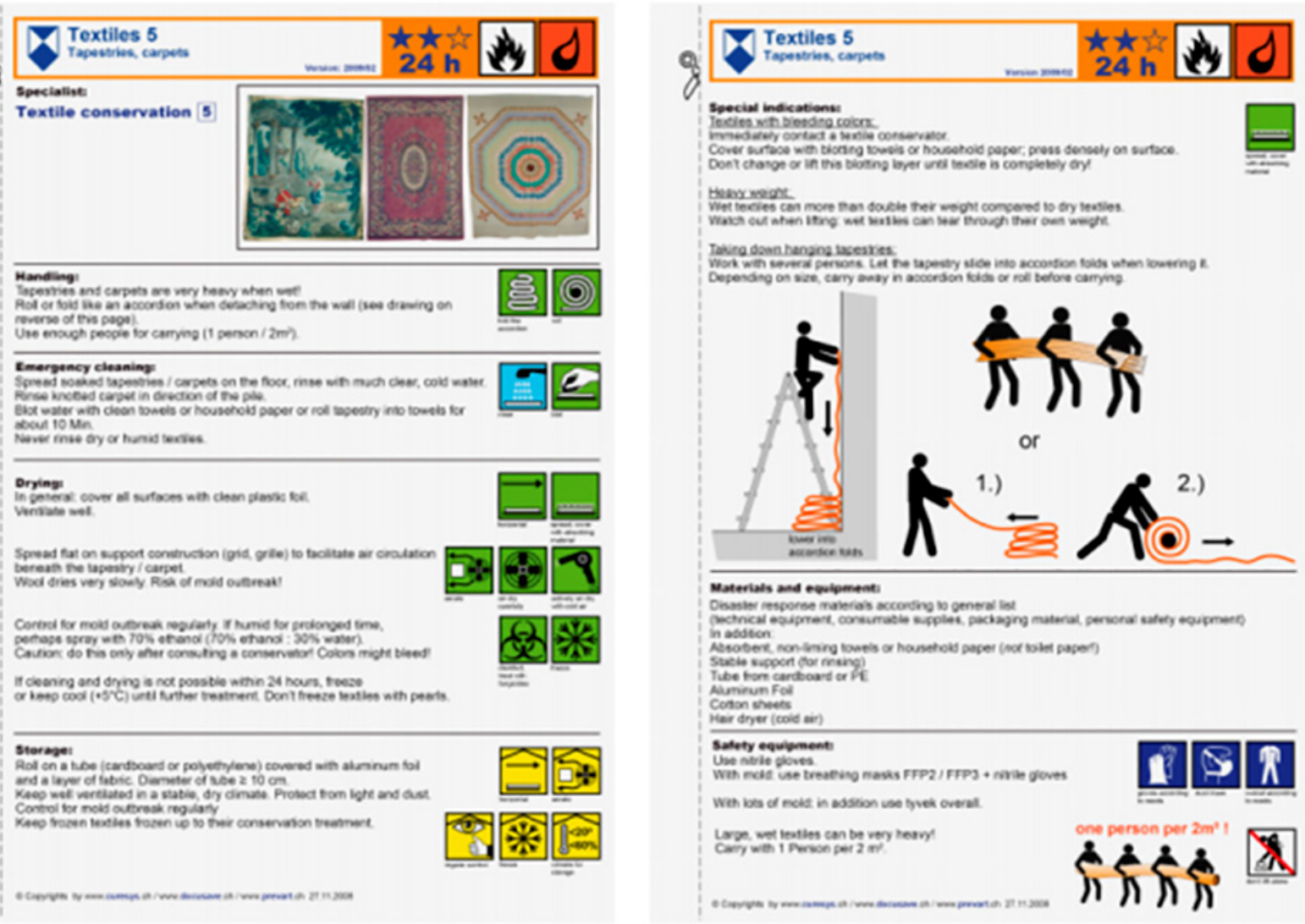

Figura 6.- Hoja de estabilización para tapices y alfombras. 2016. Fuente Prevart GmbH. 
El resultado final en la asociación de estos mecanismos:

- Logra una constancia perceptiva de los distintos elementos de información.

- Obtiene el significado y función de los distintos elementos.

- Es un modelo de doble ruta en la comunicación, al disponer de dos mecanismos de información que implica un reconocimiento global e inmediato.

Su conjunto constituye el factor determinante del software y la innovación hacia nuevos servicios [figura 7], con flujos para competir con agilidad y velocidad. La inteligencia del software se hace posible mediante el avance de los datos y su poder de procesamiento. Gracias a este avance, las aplicaciones pueden automatizar las tareas de rutina, mejorar los procesos de decisión y en última instancia, auto-dirigirse.

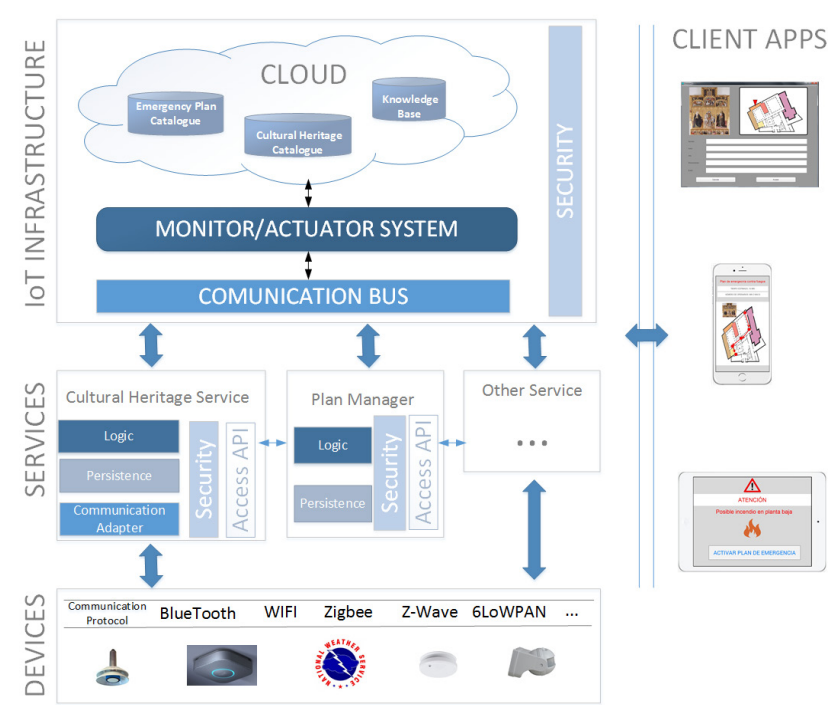

Figura 7.- Arquitectura del software de gestión de emergencias: Proyecto Museum Response and Recovery. Fuente: TaTAml Group.

- Asociar los elementos técnicos, una guía metodológica y todas las instrucciones

EI FICHERO DE EVACUACIÓN Y RESCATE es una herramienta para la coordinación y ordenación de la evacuación de los objetos.

Incluyen la propuesta en parámetros divididos por campos: con una clasificación de los datos según el análisis de la obra a varios niveles: técnico, formal, crítico y contextual. Incorporan unos 25 ítems nuevos, ignorados en la documentación de los museos que son agrupados con una cierta orientación, dirigidos a facilitar la respuesta tras un siniestro, sea de la índole que sea. La entrada de diagramas y pictogramas promueven su memorización cognitiva. [figura 6].

\section{—Estimar el plano psicológico, visual, receptor y cognitivo}

El lenguaje verbal, a pesar de su enorme riqueza, no llega a crear un entorno para la asimilación de la información bajo una situación de tensión. Este estrés, durante la emergencia, influye en la percepción y bajo esta situación la capacidad de nuestro cerebro para memorizar se reduce drásticamente, con dificultades para establecer decisiones (FIDALGO 1995) y resolver problemas.

Existen recursos tanto en el lenguaje como en la comunicación visual (repetición, frecuencia o lexicalidad), que ayudan a reducir las situaciones de fatiga o ansiedad dentro de los comportamientos de los individuos.

\section{Desarrollo estratégico: diseño y organización de la FICHA DE EVACUACIÓN Y RESCATE DE LA PINTURA}

La estrategia del nuevo sistema que aquí se plantea, está estructurada en niveles conceptuales donde los aspectos lingüísticos y visuales están representados con imágenes, gráficos y palabras. Se busca la posición correcta para cada contenido, secuenciando las imágenes que representan a los objetos y con palabras, los datos y las ideas.

Organizado en un formato a dos caras, están distribuidos campos para la identificación, localización en la sala o almacén, prioridad de rescate y procedimiento operativos de desmontaje, el peso y la carga, las instrucciones de su manipulación, los servicios y las personas con las que hay que ponerse en contacto, los recursos humanos necesarios, la dimensión de las vías de evacuación o recorridos durante su desplazamiento o el espacio para la recepción. Dentro de la prioridad del rescate, se contemplan las acciones para el riesgo del fuego por incendio o inundación.

Para cumplimentar las acciones de estabilización, durante las primeras 72 horas tras el siniestro, están incluidas gráficas y tablas de evaluación, que se registran tras el triaje, reconocimiento y clasificación.

Todas estas fichas constituyen la documentación que debe estar disponible en las salas, dentro de los dispositivos de auxilio o carros de emergencias, junto a los insumos de protección personal [figura 8].

\section{- Distribución de la primera parte}

En la cara A, los campos están en secciones: el primer bloque recoge un registro fotográfico del objeto y en un plano del edificio la ubicación de este en la sala o almacén. 


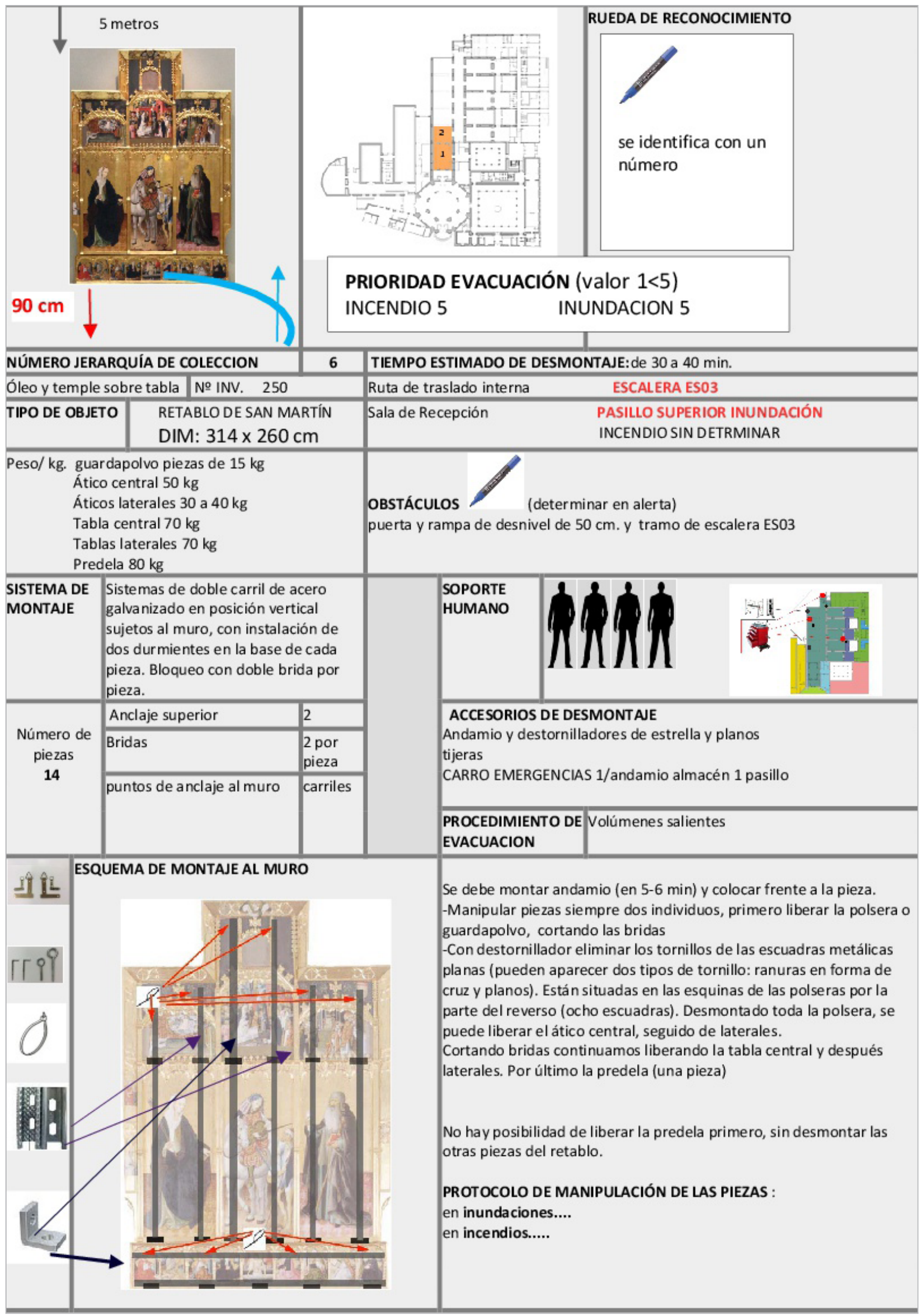

Figura 8.- Cara A de la ficha de emergencias del retablo de San Martín (medidas 314 x $260 \mathrm{~cm}$ ) del Museo de Bellas Artes de Valencia y procedente de la Cartuja de Porta Coeli. Fuente Autor. 


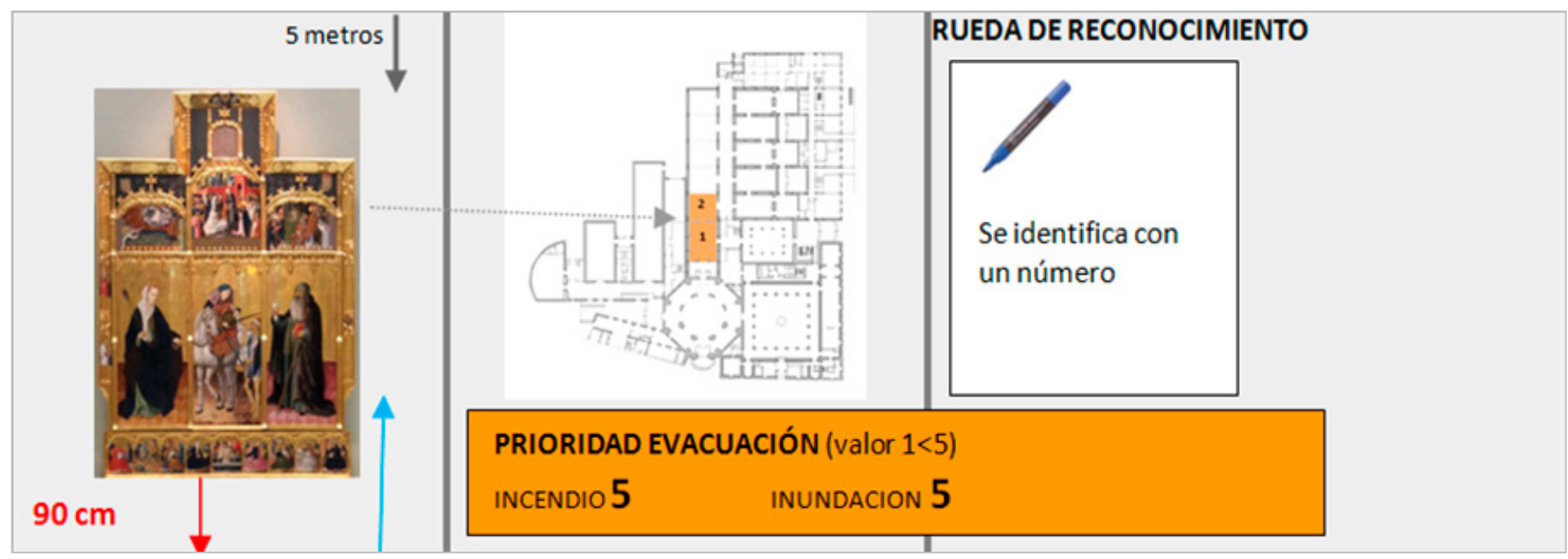

Figura 9.- Cara A de la ficha de emergencias del retablo de San Martín (medidas 314 × $260 \mathrm{~cm}$ ) del Museo de Bellas Artes de Valencia y procedente de la Cartuja de Porta Coeli. Fuente Autor.

En la figura fotográfica de la pieza, se señalan dos parámetros importantes; la distancia que existe desde la base del objeto hasta el suelo y, la distancia que existe desde el techo de la sala hasta el objeto (figura 9). Ambas mediciones espaciales tienen un objetivo concreto, permiten diseñar estrategias para el rescate frente a una emergencia por fuego o por inundación ${ }^{[9]}$. En el caso de una inundación a cota 110 para esta pieza, y de probable alcance, el riesgo compromete un contacto directo de unos $20 \mathrm{~cm}$ de contaminación. Frente a un incendio, el riesgo de un depósito masivo de hollín y partículas inflamables en la superficie, es también muy elevado por los 5 metros de distancia con el techo [figura 10]

El siguiente campo a continuación, permite señalar el número de identificación que se asignará para el triaje o rueda de reconocimiento (LIPINSKI 2012), junto al plano del edificio donde se sitúa el punto de ubicación del objeto.

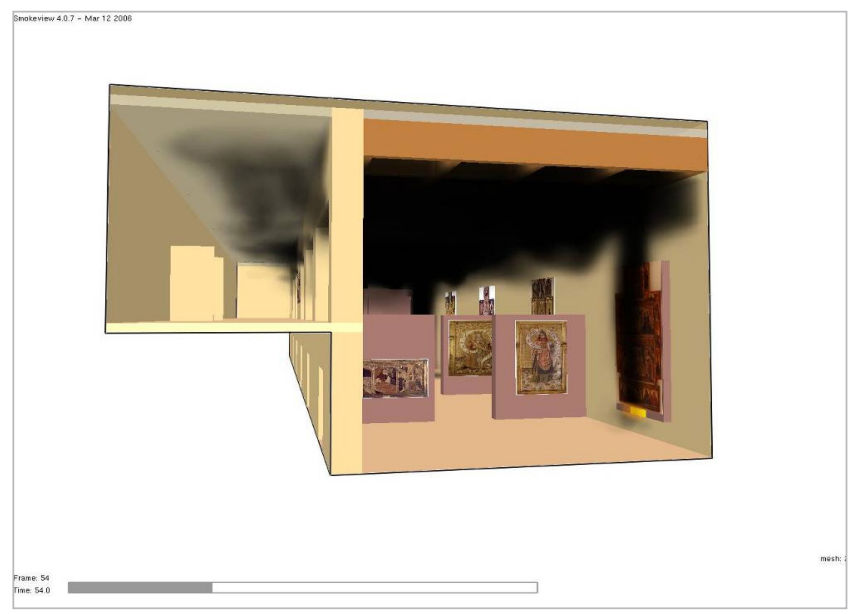

Figura 10.- Gracias a la simulación podemos estudiar el comportamiento del fuego en la sala de los retablos del Museo de Bellas Artes de Valencia. Smokeview es un software que permite predecir el comportamiento del fuego, evalúa el transporte del calor y de los gases de un incendio. Fuente: Loma Ossorio, E.
Todas las obras tienen un valor numérico (entre 1 y 5) que indica la prioridad en su rescate según el siniestro ocurrido, está calculado en base a una cotización según el valor de exposición al riesgo, creando una escala de subordinación en el rescate. Este cálculo es diferente al establecido por los conservadores de cada museo en la jerarquía de la colección o collection priority list, que se rige por otros parámetros (valor simbólico, histórico, económico, ...).

La asignación de un valor en la prioridad del rescate, está basada en la distinta progresión de los agentes de deterioro sobre los materiales. Así, aquellas obras más vulnerables serán rescatadas antes, incluso estando por debajo en el valor de la jerarquía de la colección.

Los agentes que pueden desencadenar un siniestro son muchos, podrían aparecer daños por agua, por temperatura elevada o fuego, fallos en equipos de climatización, robo, errores humanos, vandalismo, condiciones ambientales de almacenaje alteradas, sistemas de seguridad inactivos, plagas, desastres naturales o accidentes en proyectos de rehabilitación en el edificio. La característica común de todos, es la violencia con la que actúan -física, química y biológicasobre los materiales de las obras (SÁNCHEZ 2003: p.127-139).

En el segundo bloque de información [figura 11], se registran los datos más técnicos de la pieza, como su composición material, característica técnica y el número asignado en el inventario de la institución, (un valor para el acceso al sistema digital). Para calcular el soporte humano necesario para la manipulación, tiene que aparecer el valor de la carga (en kilogramos) (GOMEZ 1997) de cada pieza y por secciones como en el caso de los retablos, si se puede fragmentar.

Aunque se suele normalizar los sistemas de montaje en las instituciones, existen circunstancias que pueden modificar algunos elementos o el número de anclajes. Generalmente, el sistema de montaje al muro o tabique en las salas de exposición, no sigue un estándar que se repita, variando muchos elementos entre instituciones, incluso dentro de una sala, entre colecciones. 


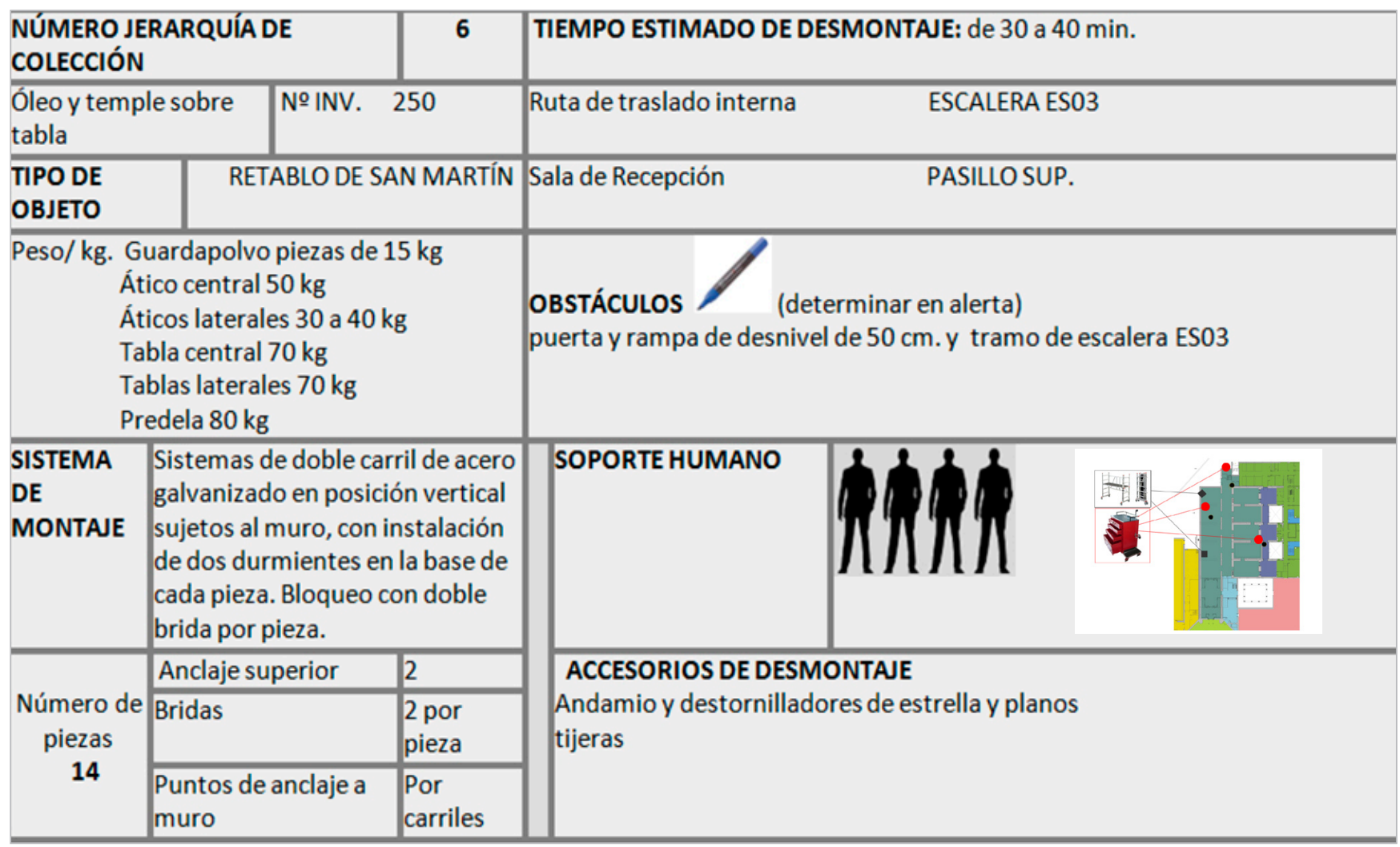

Figura 11.- Detalle de la ficha desarrollada para el plan de rescate de la colección del Museo de Bellas Artes de Valencia. Fuente: Autor.

El montaje responde totalmente, a la variedad de elementos que componen el conjunto de la obra. Esta información es muy valiosa a la hora de desmontar una pieza y la clave del éxito en la recuperación del mayor número de piezas. Es importante una descripción detallada de los puntos de anclaje al muro y de los diferentes mecanismos de bloqueo si existen [figura 12]. Son las observaciones del rendimiento operativo del desmontaje y el procedimiento de evacuación más adecuado.
El recorrido para la evacuación del objeto está estudiado y establecido para una correspondencia entre la distancia en metros del recorrido y la carga del objeto (no superior a los 25 metros). Se trata de equilibrar y compensar el esfuerzo, responsable de la fatiga y lesiones. En caso de necesidad están contemplados otros equipos humanos auxiliares de rotación y refuerzo.

Durante el rescate de la obras se unen a las condiciones extremas, las dificultades de su agarre, de algunos formatos y una posición ergonómica desfavorable ${ }^{[10]}$.

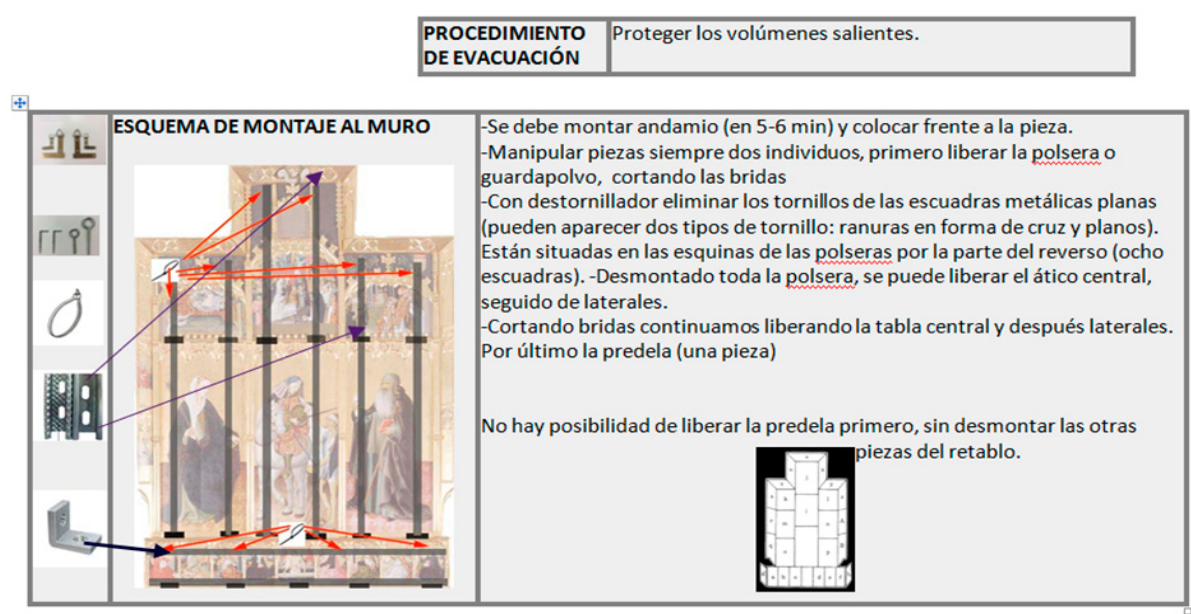

Figura 12.- Detalle de la ficha de emergencias del retablo de San Martín del Museo de Bellas Artes de Valencia. Montaje a muro: sistema de doble carril de acero galvanizado en posición vertical sujetos al muro, con instalación de dos durmientes en la base de cada pieza (muro ladrillo). Sistema anclaje superior: Doble sistema de argollas o cáncamo cerrado bloqueados con bridas. Sistema de soporte inferior: doble durmiente de acero galvanizado. Fuente: Autor. 


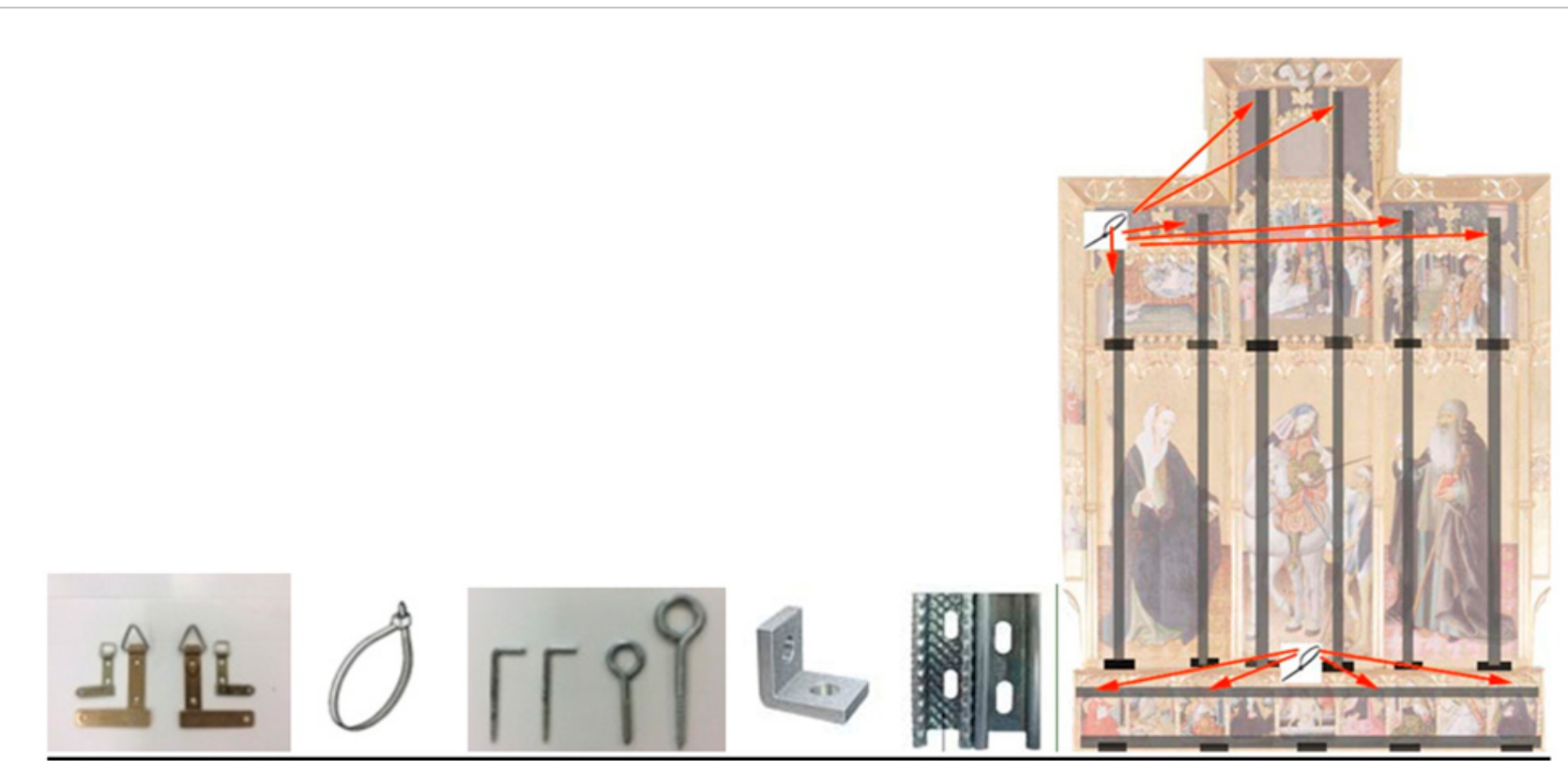

Figura 13.- Detalle de los elementos de anclaje de un retablo. Fuente: Autor.

En la ficha también está asignada la sala de recepción de los objetos que se establece como sala de reconocimiento donde se activa el circuito de los primeros tratamientos preliminares encaminados a la estabilización de los materiales.

En el campo del esquema del montaje aparece una imagen con los puntos de anclaje al muro, se especifican las diferentes tipologías de elementos utilizados acompañados de pictogramas o fotografías [figura 13]. Estas imágenes ayudan a localizar los anclajes, evitando accidentes durante el rescate de los objetos.

Al no tratarse de fichas cerradas, se pueden añadir y mejorar los datos recogidos en este ejemplo, que serán evidentes cuando se establezcan los simulacros y la formación de los equipos, permitiendo analizar las carencias del modelo.

\section{—Distribución de la segunda hoja}

En la cara B de esta ficha, los campos están orientados para el registro de mediciones y monitoreo del ambiente. Estos campos están consignados por el equipo de intervención y responsables de la recepción y activación de la rueda de reconocimiento (TSE 2007) [figura 14]. Este equipo deberá conocer en profundidad aquellos valores de conservación de los materiales, que modificados durante el siniestro, deberán recuperarse gradualmente para la estabilización de las obras.

Un procedimiento común de evaluación de los objetos del museo, como el pH, afectará al valor acidez/ alcalinidad de las obras y su ambiente, con acción bioquímica en muchos soportes y contenedores de los objetos.

Dentro del área de observación, se determina una monitorización y su frecuencia que varía según el siniestro y las consignas de los tratamientos necesarios. Para la estabilización del ambiente y de los objetos se miden con la frecuencia designada y en las áreas donde estén depositadas las obras, los valores de humedad relativa, temperatura y lux (aparecerán en la gráfica superior) permitiendo el seguimiento de las condiciones atmosféricas.

Cada colección determina su lista de actividades, una buena respuesta frente a una emergencia implica un conjunto de acciones que deben realizarse sin improvisación [figura 15].

Un modelo de gestión de riesgos consiste en construir la información mínima que permita calcular el riesgo que se va a asumir y prever las reservas (financieras, sociales, psicológicas, emocionales, etc.) que permitirían la supervivencia en condiciones adecuadas (SÁNCHEZ et al. 2015)

\section{Test de stress o prueba de utilidad en el futuro}

Para la evaluación y eficacia del sistema utilizado en la FICHA DE EVACUACIÓN Y RESCATE, debe realizarse un ensayo de adiestramiento práctico con simulacros anuales, poniendo a prueba los contenidos, su diseño, las carencias y debilidades sobre las que trabajar [figura 16]. 


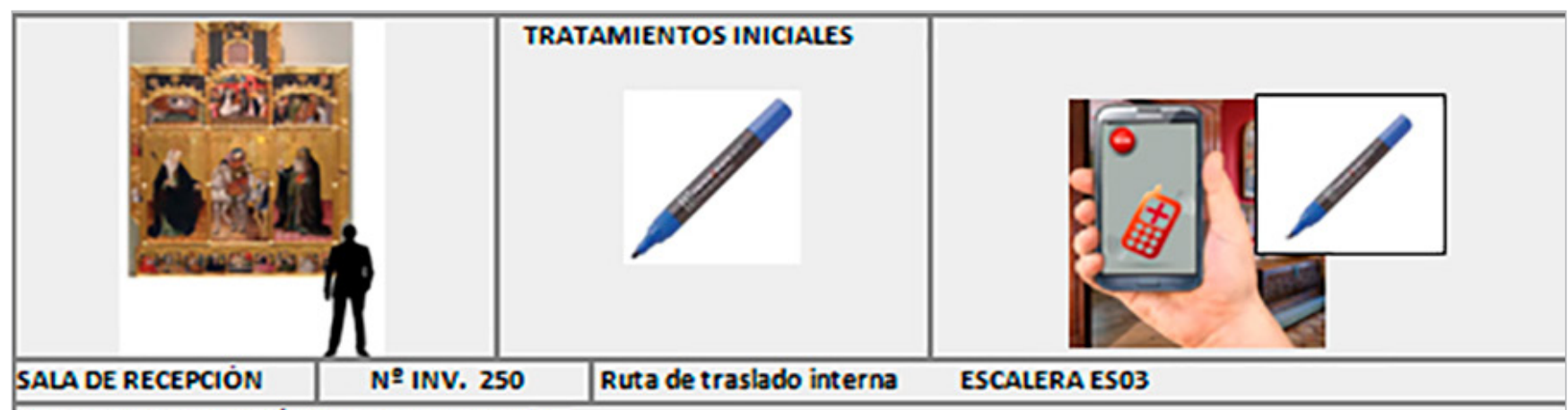

AREA DE OBSERVACIÓN: CONTROL DE HR /T
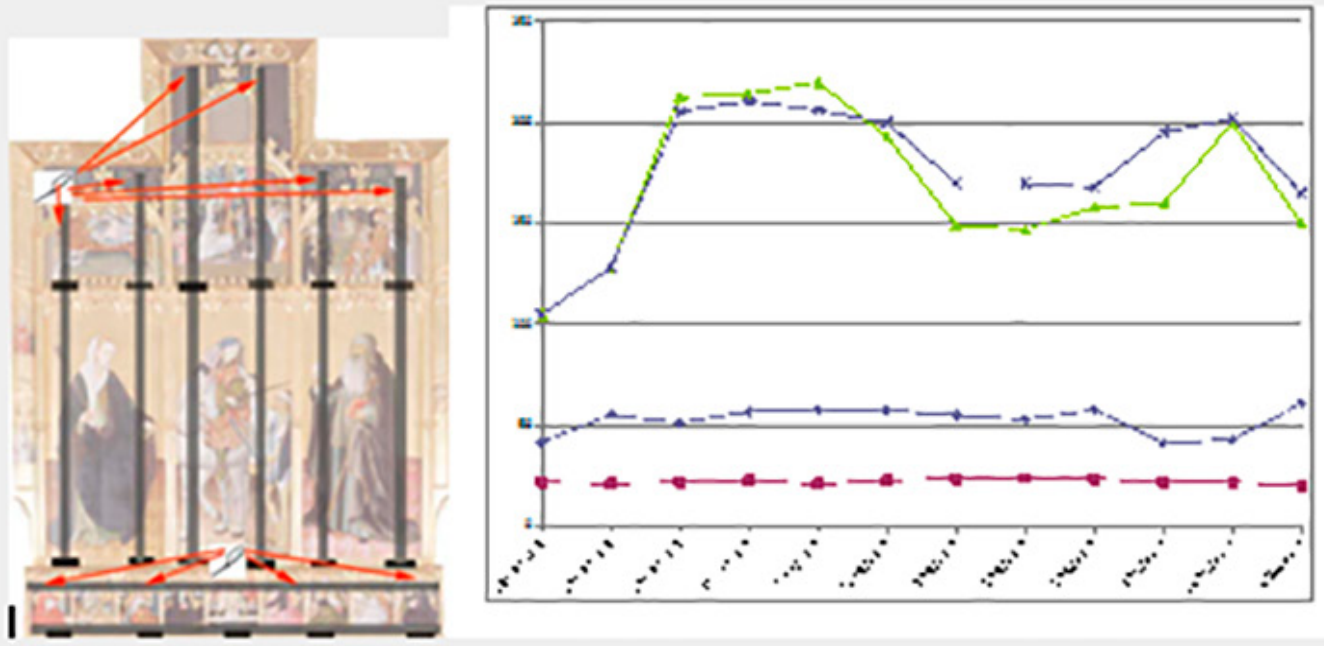

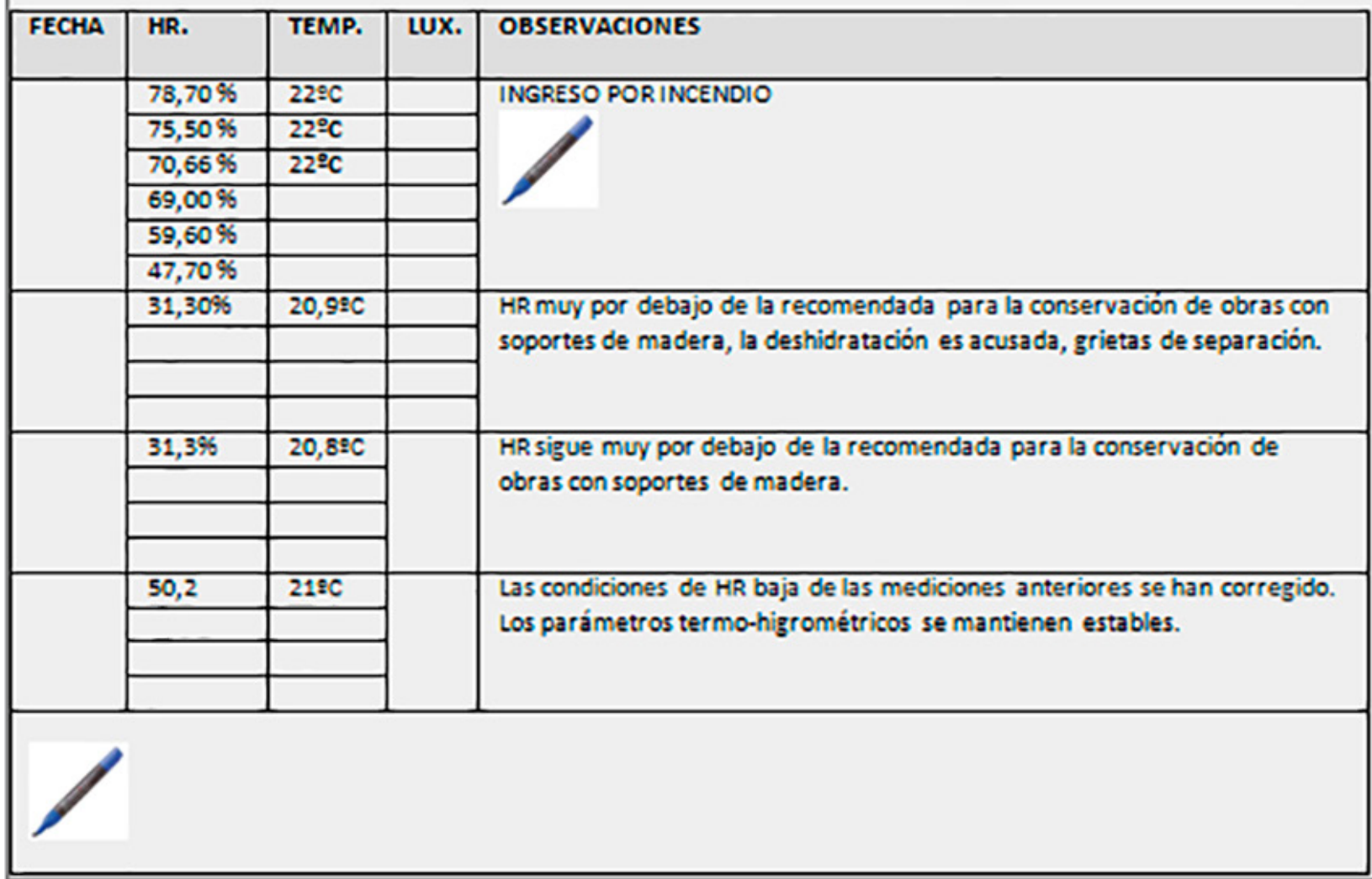

Figura 14.- Cara B de la ficha de emergencias del retablo de San Martín del Museo de Bellas Artes de Valencia. Fuente: Autor. 


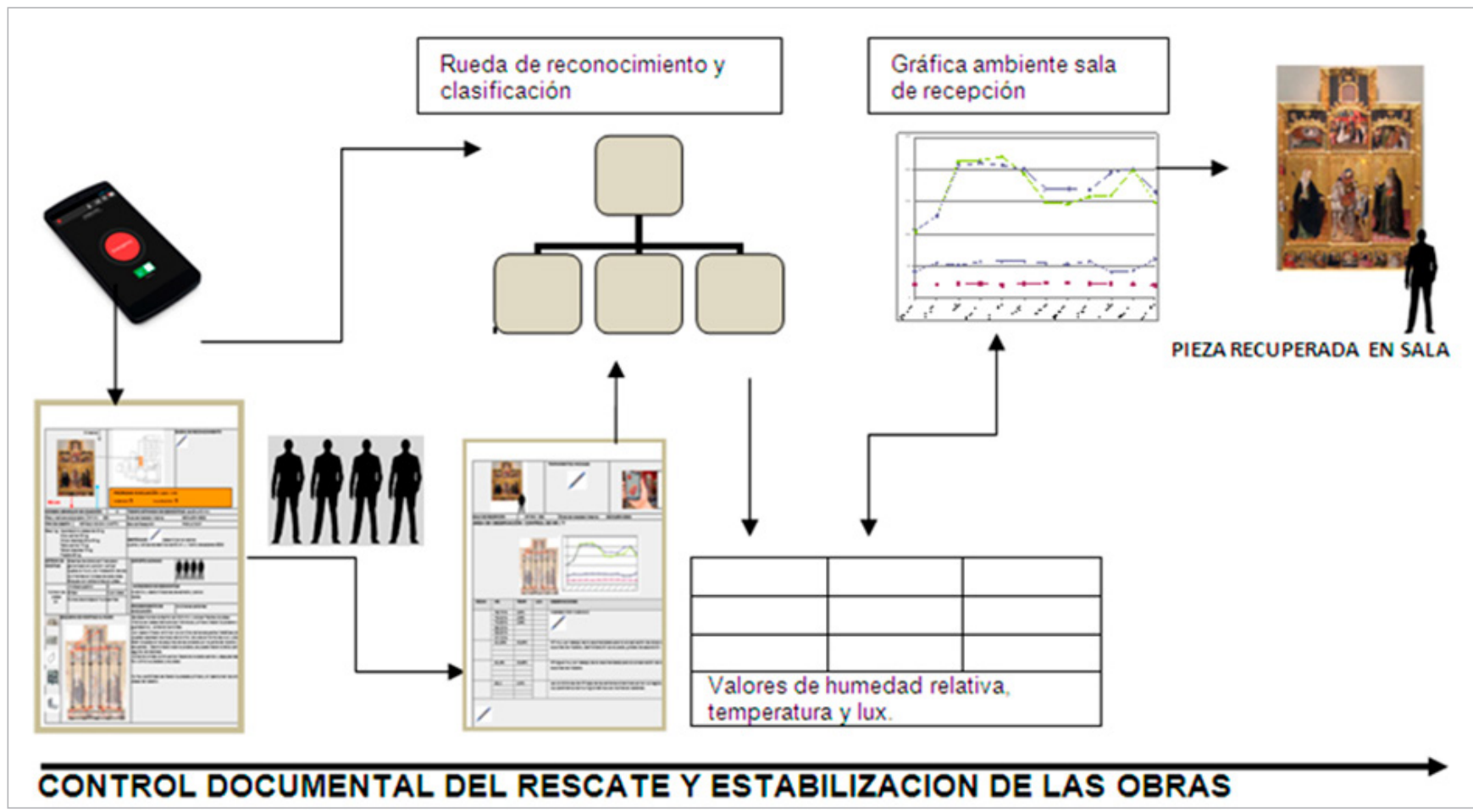

Figura 15.- Modelo de secuencia del control documental: ejemplo con rescate y estabilización durante una crisis para la colección. Fuente: Autor

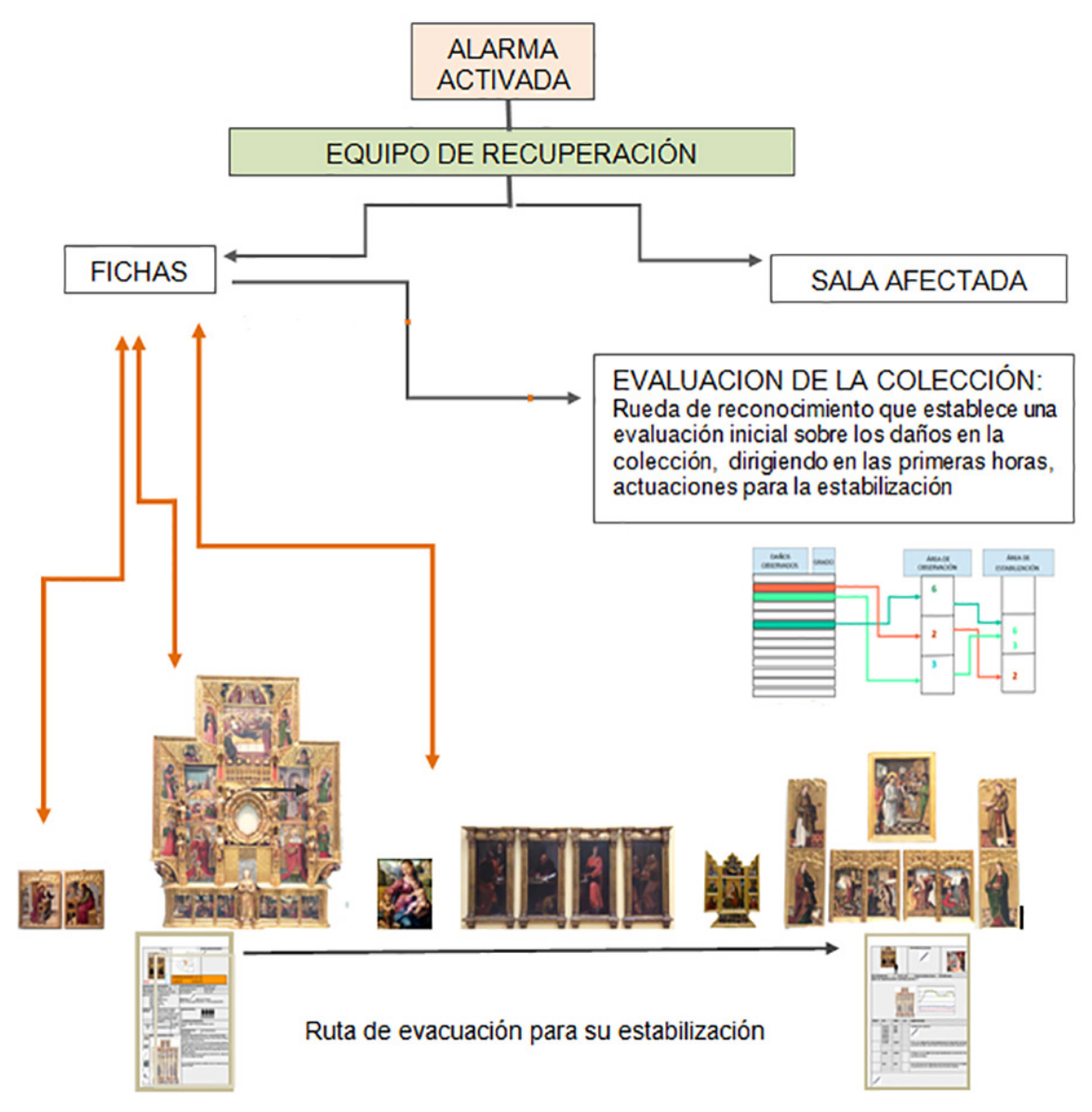

Figura 16.- Esquema visual de actuaciones del equipo de recuperación. Fuente: Autor. 


\section{Conclusión}

La ausencia sobre normativas en el rescate de los objetos de las colecciones y su registro, es una oportunidad para diseñar nuevas estrategias. En las fichas para la evacuación y rescate de la pintura de caballete de la colección del Museo de Bellas Artes de Valencia se han introducido nuevos procedimientos, asociando en un mismo formato las actividades del rescate, evaluación y estabilización de los objetos.

En el ámbito de la comunicación, se hace uso de recursos didácticos como la asociación de textos, palabras, clausulas - letras, unidas a pictogramas o gráficos, para que el receptor sea capaz de extraer la información con facilidad. Es un modelo que reúne las fortalezas señaladas en los patrones y herramientas analizados.

Para mejorar los procesos de decisión se ha determinado una jerarquía de rescate diferente a la jerarquía de la colección. Al aplicar una jerarquía de rescate, se ha considerado la acción de los riesgos con un cálculo matemático, buscando multiplicar las opciones de evacuación frente a los siniestros.

Se ha enfatizado en la prioridad descriptiva del desmontaje de los objetos dentro de la descripción del montaje de las colecciones, señalando sus diferencias. Se ha insistido en la importancia establecida con la relación de la carga del objeto, el soporte humano y los trayectos de evacuación, a la hora de evitar nuevos accidentes y lesiones. En cualquier situación crítica, una actuación masiva y desordenada puede generar más caos.

El procedimiento de este modelo se podrá adaptar a otras fichas de rescate. El planteamiento es construir un registro de toda la colección con las fichas que cada institución consideren adecuadas para sus tipologías y a través de un acceso online con una aplicación (App) en dispositivos móviles (smartphone), desarrollar una herramienta de trabajo equivalente sin necesidad de conexión a Internet, garantizando que la información se pueda utilizar ante cualquier siniestro.

El equipo de investigadores TaTAml Group (Techniques and Tools for Ambient Intelligence $\odot$ 2016), ha iniciado el desarrollo de una aplicación que utilizará este modelo de fichas para la evacuación y rescate como soporte inteligente durante los diferentes siniestros. Constituyen uno de los 14 equipos que lideran el departamento de Sistemas Informáticos y Computación de la Universidad Politécnica de Valencia. A través de esta aplicación móvil, además de vincular la información al registro de la institución, se podrá acceder a más información de la que se recoge en la ficha y los responsables del rescate y equipos de primera intervención podrán durante las horas críticas del siniestro, establecer conexión con otros especialistas. El objetivo es conseguir que esta aplicación sea una de las herramientas favoritas e imprescindibles en el smartphone de los usuarios responsables en los equipos de emergencias.

Cada desastre natural o no natural, donde se ve afectado el patrimonio cultural, sirve como recordatorio de que las instituciones deberían tener planes apropiados sin poner en peligro las colecciones. Una responsabilidad trasladable a directores, gerentes, administraciones locales y responsables políticos.

\section{Notas}

[1] Según la autora Anne Ambourouè de la Ecole du Patromoine Africain y Gaël de Guïchen, en La documentación de las colecciones de los museos: ¿Por qué? ¿Cómo? Guía práctica del ICCROM-UNESCO (2010), gracias a la documentación básica administrativa de las colecciones, se puede, con rapidez y eficiencia: establecer una comprobación de propiedad, localizar un objeto específico, conocer el número total de los objetos que componen la colección, establecer la identidad (siempre exclusiva) de un objeto y realizar un control del inventario, relacionar la documentación con un objeto, acceder a la documentación de manera eficiente y económica (ahorrándose espacio, tiempo y trabajo), contribuyendo a la seguridad de las colecciones.

[2] Comité Internacional para la Documentación, perteneciente al Consejo Internacional de Museos. Ficha técnica $n^{\circ} 1$ del CIDOC, Llegada de un objeto al museo: etapas del proceso de registro y catalogación, 1994, referente al ingreso/inventariado de los objetos.

[3] El Sistema Integrado de Documentación y Gestión Museográfica, desarrollado entre 1996 y 2010 en España por el Ministerio de Cultura, la Subdirección General de Museos Estatales y Subdirección General de Tecnologías y Sistemas de Información está implantado en 52 museos estatales y 40 de otras titularidades, con convenios firmados para otros museos en el futuro.

[4] Para la consulta de documentación de referencia de instituciones como el Museo del Prado, Museo Thyssen o el Museo Guggenheim de Bilbao, es necesaria una solicitud de investigación a los responsables correspondientes dado su contenido confidencial.

[5] Dossier de formularios: fichas de cada elemento priorizado, fichas para registrar daños y fichas para evaluación de daños. Plan nacional de Emergencias y Gestión de riesgos en el patrimonio cultural, p 106; p 111.

[6] Una organización nacional sin fines de lucro dedicada a la conservación del patrimonio cultural de los Estados Unidos.

[7] Para descargar esta aplicación, se debe buscar "ERS: Emergency response and salvage Wheel". [ERS Mobile App].

[8] The Council of State Archivists, EEUU. (http://www. heritageemergency.org/) 
[9] El comportamiento de fuego o del agua, sea en un incendio o una inundación, es completamente diferente y actúan desde distintos alcances.

[10] Ministerio de Educación, Cultura y Deporte Frágil. Curso sobre manipulación de bienes culturales. Secretaría General Técnica. Centro de Publicaciones. 2013

\section{Bibliografía}

AMBOUROUĖ AVARO, A; GUÏCHEN, G. de. (2010). La documentación de las colecciones de los museos: ¿Por qué? ¿Cómo? [en línea]. @ UNESCO, ICCROM et EPA.

ARISTEGUI ANDUIZA, B; SANZ LÓPEZ DE HEREDIA, A. (2004) Implantación de un plan de conservación preventiva. Akobe: restauración y conservación de bienes culturales= ondasunen artapen eta berriztapena, no 5, p. 29-32.

CARRETERO PÉREZ, A. et al (1998). Normalización documental de museos: elementos para una aplicación informática de gestión museográfica. Ministerio de Educación y Cultura, Dirección General de Bellas Artes y Bienes Culturales.

CARRETERO PÉREZ, A. (1997). La documentación en los museos: una visión general. Museo, vol. 2, p. 11-29.

CHULIÁ BLANCO, I. (2016). La gestión de las emergencias en el patrimonio cultural: procedimientos de asistencia técnica en el Museo de Bellas Artes de Valencia frente a las catástrofes naturales y tecnológicas. Tesis Doctoral. Universidad Politécnica de Valencia.

CULUBRET WORMS, B., et al. (2008). Guía para un plan de protección de colecciones ante emergencias, Madrid: Ministerio de Cultura. Secretaría General Técnica. Centro de publicaciones.

DORGE, V.; JONES, S. L. (2004). Creación de un plan de emergencia. Guía para museos y otras instituciones culturales.

FABRE MURILLO, J.; LORENTE ALGORA, M. (2009). El archivo administrativo. II. Planificación informática. Análisis del soporte técnico en el desarrollo de la implantación informática de DOMUS, versión usuario y versión web. p. 51.

FIDALGO VEGA, M. (1995). NTP 390: La conducta humana ante situaciones de emergencia: análisis de proceso en la conducta individual.

GOMEZ, J.; AMILLO, H. (1997). Guía Técnica para la evaluación y prevención de los riesgos relativos a la Manipulación manual de cargas. Instituto Nacional de Seguridad e Higiene en el Trabajo.

LEDESMA RODRÍGUEZ, R. (1992). La documentación en el Patrimonio Nacional. Política científica, 1992, no 34, p. 33-37.

LIPINSKI J. (2012). A triage unit for storm-damaged artwork in the Blooklyn Navy Yard. En [https://www.politico.com/states/new- york/albany/story/2012/11/a-triage-unit-for-storm-damagedartwork-in-the-brooklyn-navy-yard-067223]

MCCRACKEN, P. (1995). Disaster planning in museums and libraries: A critical literature review. Katharine Sharp Review; no. 001, Summer 1995.

MICHALSKI, S. (2009). Preservación de las colecciones. Instituto Canadiense de Conservación.

OVIEDO, G. L. (2004). La definición del concepto de percepción en psicología con base en la teoría Gestalt. Revista de estudios sociales, 2004 , no 18 , p. 89-96.

SÁNCHEZ DÍAZ, J.; CARSÍ CUBEL, J.; PENADÉS, M. C. (2015) Un entorno de gestión de casos para la resolución flexible de emergencias.

SÁNCHEZ HERNANPÉREZ A. (2003). Las primeras 48 horas después de un desastre. Revista Catalana d'Arxivística. 2003 p.127-139.

TSE, S. (2007). Guidelines for $p H$ measurement in conservation. Canada. Department of Canadian Heritage. Canadian Conservation Institute.

VON LERBER, K. (2014) Organizational tools for salvage operations. En ICOMCC 17th Triennal Conference Preprints Melbourne, 2004. p.15-19. 


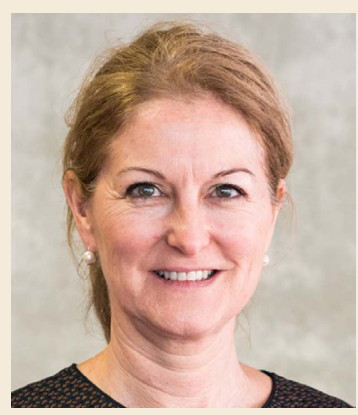

\section{Inmaculada Chuliá Blanco}

chuliablanco@gmail.com

Instituto Valenciano de Conservación, Restauración e Investigación de la Generalitat Valenciana.

Doctora por la Universidad Politécnica de Valencia, en el programa de Ciencia y Restauración del Patrimonio Histórico Artístico en el 2015, y Licenciada en Bellas Artes, con las especialidades en Pintura y Conservación y Restauración de Bienes Culturales (1984-1991), por la Facultad de BBAA de Valencia.

Desde junio de 2006, pertenece al equipo de investigadores del Instituto Valenciano de Conservación, Restauración e Investigación de la Generalitat Valenciana. Sus investigaciones están relacionadas con la gestión de las emergencias en el Patrimonio Cultural y los procedimientos de asistencia técnica. Pertenece desde 2015, a la comisión de seguimiento del Plan Nacional de Emergencias y Gestión de Riesgos en el Patrimonio Cultural, que se creó por parte del Ministerio de Educación, Cultura y Deporte para dar una respuesta rápida por emergencia o catástrofe que afecte al Patrimonio cultural. Imparte docencia en el Máster de Patrimonio cultural: identificación, análisis y gestión, de la Universidad de Valencia desde el 2016, con formación como "Introducción a las emergencias del patrimonio cultural y la respuesta institucional" y la "Identificación de los diez agentes de deterioro para el Patrimonio".

\section{Artículo enviado el 05/05/2017}

Artículo aceptado el 15/03/2018 